\title{
On the response of the European climate to solar/geomagnetic long-term activity
}

\author{
Venera Dobrica $^{1,{ }^{\star}}$, Crisan Demetrescu ${ }^{1}$, Georgeta Maris ${ }^{1}$ \\ ${ }^{1}$ Institute of Geodynamics, Romanian Academy, Bucharest, Romania
}

\author{
Article history \\ Received January 21, 2010; accepted July 29, 2010. \\ Subject classification: \\ European surface air temperature, Climate variability, Solar and geomagnetic activity, Solar-terrestrial interaction.
}

\section{ABSTRACT}

The response of the European climate to long-term solar/geomagnetic activity is investigated using surface-air temperature and solar/geomagnetic indices. A set of 21 time series of air temperatures measured at European stations between 1900 and 2006, and 4 European and 14 Romanian stations with 150-year-long records, were used. Strong and coherent solar signals were found at Schwabe and Hale solar-cycle timescales, with peakto-trough amplitudes of several degrees, and $0.6{ }^{\circ} \mathrm{C}$ to $0.8^{\circ} \mathrm{C}$, respectively. Interdecadal and centennial trends as defined by 11-year and 22-year running averages, respectively, of the annual mean time series differ significantly from corresponding trends in solar/geomagnetic activity, which indicates the presence of temperature variations at a 40-year timescale that are possibly related to the internal dynamics of the atmospheric system. The data show similar temporal behaviors at all of the stations analyzed, with amplitude differences that can be understood in terms of large-scale atmospheric circulation patterns that are influenced by the solar/geomagnetic forcing at the corresponding timescales, although with local intensity differences.

\section{Introduction}

The solar influence on terrestrial climate cannot be measured directly. Correlations between solar activity indices and climate parameters have been found, such as the wellknown correlation between the average temperature of the northern hemisphere and the length of the solar cycle [FriisChristensen and Lassen 1991]. Recently, many studies have focused on the Sun-Earth climate relationship, providing evidence for a possible solar influence on some climatic parameters at solar-cycle timescales, such as ground and seasurface temperatures, precipitation and pressure [Le Mouël et al. 2005, Le Mouël et al. 2008, Le Mouël et al. 2009, van Loon et al. 2007, Dobrica et al. 2009], and also higher in the atmosphere [Labitzke and van Loon 1988, Haigh 2007, Labitzke 2005].

The data series of sunspot numbers has been reconstructed at the multi-millenary scale, based on ${ }^{10} \mathrm{Be}$ data and ${ }^{14} \mathrm{C}$ data [Usoskin et al. 2003], and on the concentration of ${ }^{14} \mathrm{C}$ in tree rings [Solanki et al. 2004]. Usoskin et al. [2006] took into account also the reconstructed geomagnetic dipole moment over the last 7,000 years, as derived by Korte and Constable [2005]. The reconstructed sunspot number showed relationships with the various reconstructions of the Earth surface temperature [Usoskin et al. 2005]. Also, Scafetta and West [2007] reported a solar signature in the northern hemisphere mean temperatures over the last millennium.

Geomagnetic activity as a forcing agent of the climatic variations has been investigated in several studies [Cliver et al. 1998, Bucha and Bucha Jr. 1998, Bucha and Bucha Jr. 2002, El-Borie and Al-Thoyaib 2006, Valev 2006]. These studies have shown statistically significant correlation coefficients at the $99 \%$ confidence level between geomagnetic activity and several climatic parameters, such as the sea-level atmospheric pressure and the surface-air temperature. Geomagnetic indices that characterize the solar quiet daily variations, designed by Le Mouël et al. [2005], have shown over the last century the same long-term behavior as the surface-air temperature records from the USA, Europe and Australia, and as the pressure data from Europe [Le Mouël et al. 2008, 2009]; namely, an increase from 1900 to 1950, followed by a decrease from 1950 to 1975 , and then an increase again. These studies concluded that the solar influence on European climate is not stationary: it depends on the season of the year, with it being more effective in winter.

While statistical studies have shown strong correlations of solar activity parameters and climatological parameters, the reasons for these changes are not fully understood. It appears that the effects of solar forcing on the terrestrial climate taken into account in global circulation models by variations of total solar irradiance are too small to be of major importance for climate change (see review by Haigh [2007]). Such links and the relative contribution of either solar or geomagnetic effects on climate, as well as the associated physical processes [e.g. de Jager and Usoskin 


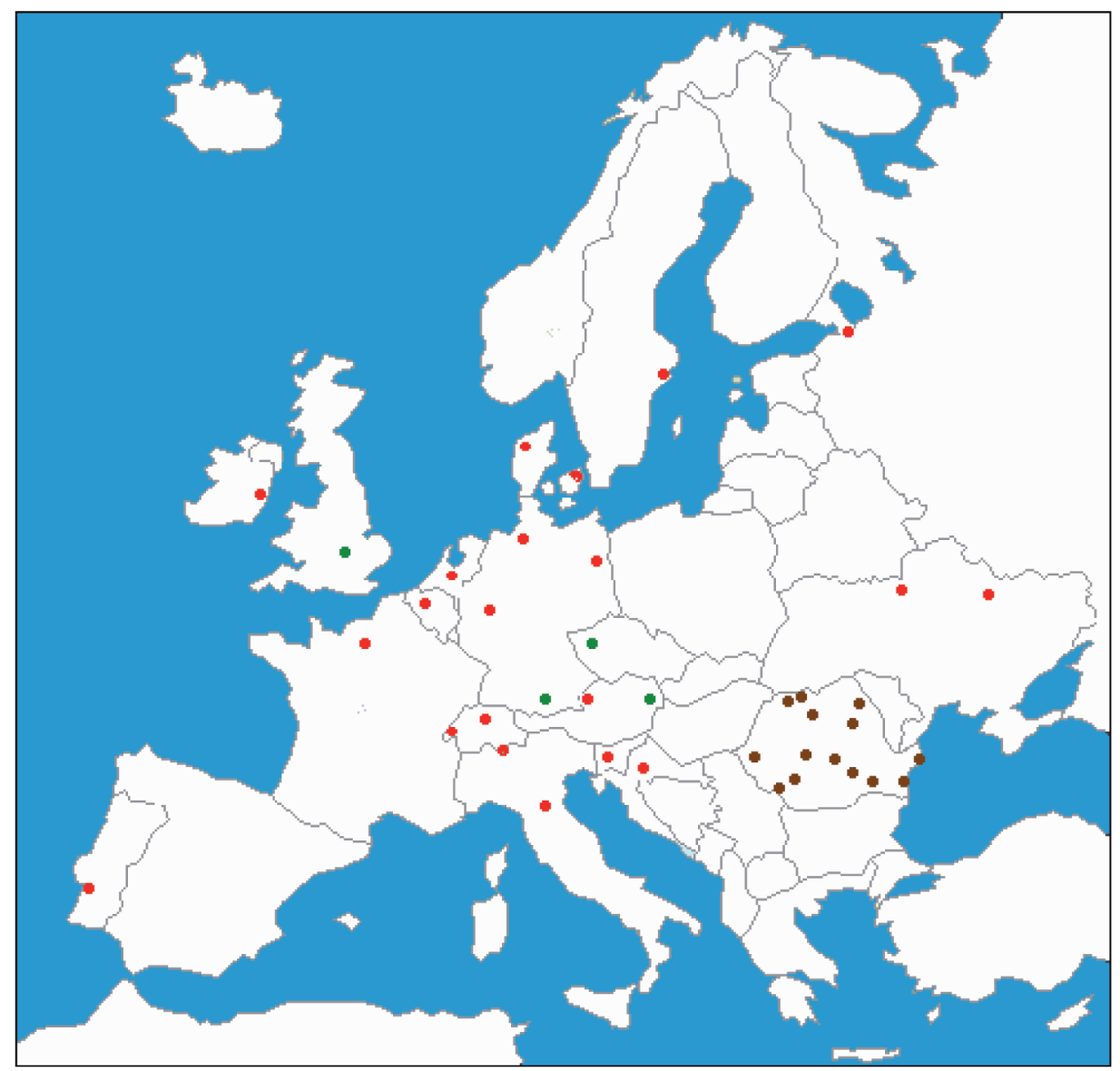

Figure 1. Location of the meteorological stations. Red dots, 21 European stations (European Climate Assessment and Dataset); brown dots, 14 Romanian stations; green dots, four European stations with long records.

2006], are still a matter of debate and future studies. An extended discussion and evaluation of possible drivers of climate change on temporal scales from 10 to $10^{4}$ year timescales was published recently by Courtillot et al. [2007]. They included in their discussion the so-called arheomagnetic jerks [Gallet et al. 2003] and a mechanism involving variations in the dipole tilt that result in enhanced cosmic-ray-induced nucleation of clouds. They concluded, however, that "no forcing factor, be it changes in $\mathrm{CO}_{2}$ concentration in the atmosphere or changes in cosmic-ray flux modulated by solar activity and geomagnetism, or possibly other factors, can at present be neglected or shown to be the overwhelming single driver of climate change in past centuries» [Courtillot et al. 2007]. A comprehensive reference list regarding the individual possible climate drivers can also be found in Courtillot et al. [2007].

Our interest in this study is to make evident the solar/magnetic activity signals at timescales longer than usually studied, and to characterize these regarding their time evolution. We do not attempt to decide on the physical processes behind the correlations we find. The present study is an extension of our previous study [Dobrica et al. 2009], in which we focused on the long-term variations in climatic parameters over Romania and the solar/geomagnetic signatures that they contained. Here, we have completed our
Romanian temperature and European records database with the data from 21 meteorological stations in Europe. The temperature data and the way we have processed them, as well as the solar/geomagnetic long-term activities, are discussed in the next section. The results of the processing are presented in Section 3 and discussed in Section 4. The last section is dedicated to some conclusions.

\section{Data and processing}

\section{Space climate data}

Solar variability is related to the phenomena that take place on the surface of the Sun and in its atmosphere, and it is described by so-called indices of solar activity. The solar activity is widely described by the sunspot number, this index having the longest time series of direct observations, which started in 1610. In our analysis, we have used the annual means of the sunspot number, $\mathrm{R}$, the database for which is available at ftp:/ / ftp.ngdc.noaa.gov/STP/SOLAR_DATA/ SUNSPOTNUMBER/INTERNATIONAL/YEARLY.

Geomagnetic activity is controlled by the Sun, via the solar wind (SW) and the heliospheric magnetic field (HMF), and its intensity depends on the phase of the solar cycle. At the global scale, the perturbation level of the geomagnetic field, which is driven by the ionospheric and magnetospheric 


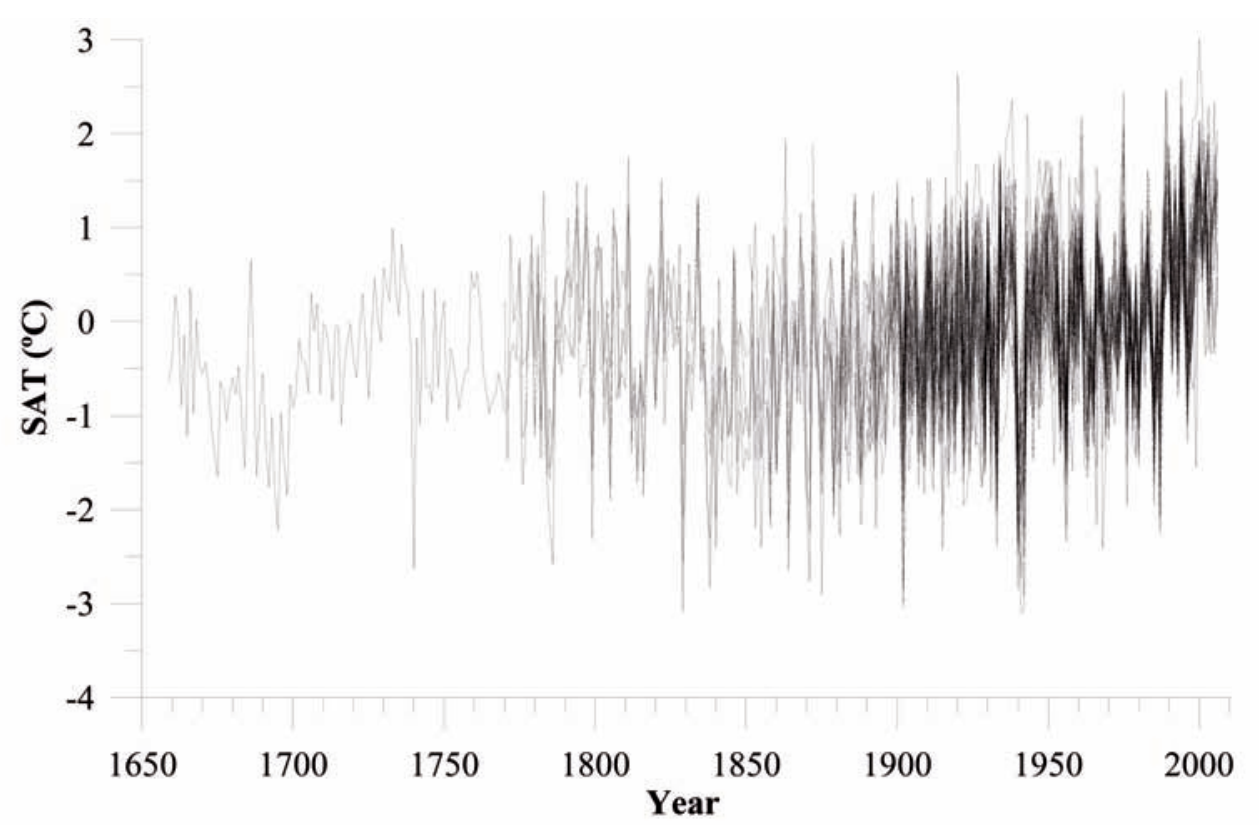

Figure 2. Surface-air temperature anomalies at all of the stations analyzed, relative to the 1961-1990 means.

currents as a consequence of the interaction of the SW and the HFM with the magnetosphere, is described by means of geomagnetic indices. Among these, the geomagnetic aa index covers the longest time span, since 1868 [Mayaud 1972, 1980]. The annual means of the geomagnetic aa index are available at http:/ / isgi.latmos.ipsl.fr/lesdonne.htm. It should be noted that we corrected the data prior to 1957 by $+3 \mathrm{nT}$, according to Svalgaard and Cliver [2007].

It is well known that the long-term evolution of solar/geomagnetic activities is characterized by variations at various timescales, of which the sunspot cycle is well known. The presence of variations at timescales of 22-year (Hale) and 80-90-year (Gleissberg) solar cycles in the geomagnetic activity, as described by the aa, was discussed by Demetrescu and Dobrica [2008], along with the inter-diurnal variability [Svalgaard and Cliver 2007] and the inter-hourly variability [Svalgaard and Cliver 2005] geomagnetic indices.

\section{European terrestrial climate data}

A set of 21 time series of air temperatures measured at European stations between 1900 and 2006 has been analyzed, to which the time series from 4 European stations and 14 Romanian stations with 150-year-long records (or longer) were added.

The daily mean data of surface-air temperatures from 21 European meteorological stations for this 1901-2006 time interval (with as few gaps as possible) were retrieved from the European Climate Assessment and Dataset database, available at http:/ / eca.knmi.nl/dailydata/index.php. Yearly means were computed from these data. The Romanian dataset consisting of 150-year-long records of yearly mean air temperatures from 14 weather stations in the time interval of 1850-2004, was presented by Dobrica et al. [2009]. We also included in our database the longest homogeneous instrumental temperature series in the World, the central England temperature record, which dates back to 1659 [Manley 1974, Parker et al. 1992], and three other similar temperature records dating back to the middle of the 18th century: namely of Hohenpeissenberg, Germany (17812002), Vienna, Austria (1775-2002), and Prague, Czech Republic (1770-2002) (Jan Safanda, personal communication, 2005), computed as yearly averages. The spatial cover of these meteorological weather stations is shown in Figure 1.

The surface-air temperature variations for all of the analyzed stations, in terms of anomalies relative to the mean over the time interval of 1961-1990, is shown in Figure 2. The coherence of the variation at all of the stations and the existence of interdecadal and longer timescale variations can easily be seen.

Using the multi-taper method spectral analysis technique, Dobrica et al. [2009] showed the presence of variations of short periods (2-7 years; significance level, 84\%-92\%), decadal variations with a period of $\sim 11$ years (significance level, $90 \%$ ) and variations with longer periods, as 30 years and even longer (significance level, 95\%) in the Romanian temperature data.

Generally, long-term instrumental temperature records have been analyzed for evidence of variations of long periods. They have showed clear indications of variations on timescales of about 2.2 to 2.4 years and of 3 to 4 years, but on longer timescales, individual records show peaks at different frequencies. Using enhanced wavelet analysis, Johnson [2009] found the third and the ninth harmonics of the Hale solar cycle both in the sunspot number data and in the temperature records from central England.

An example of the processing of temperature data from one individual station (Potsdam) is given in Figure 3. After filtering out the short-term variations in temperature data by applying a 4-year running mean low-pass filter, the series are 


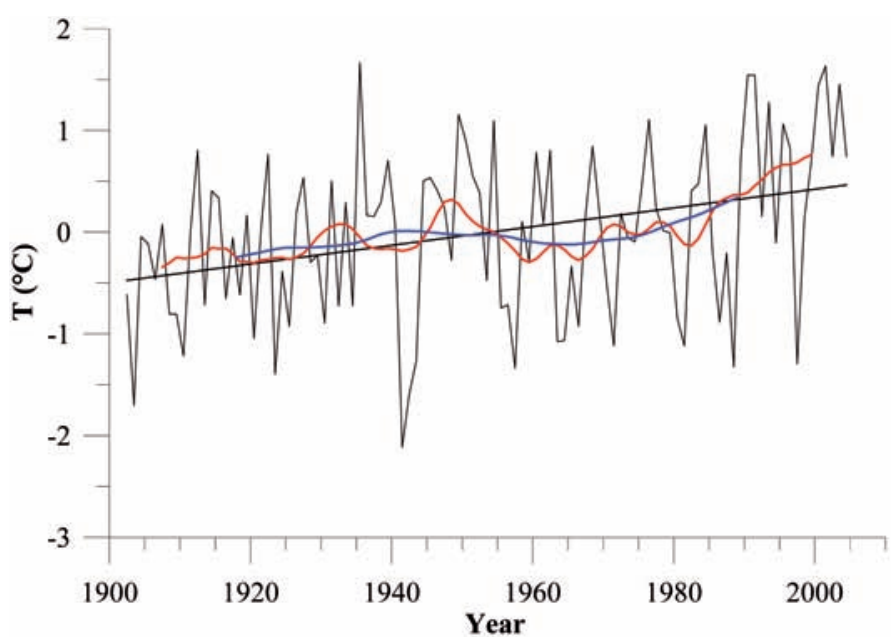

Figure 3. Surface-air temperatures at Potsdam station. Black, linear trend; red, interdecadal trend; blue, centennial trend.

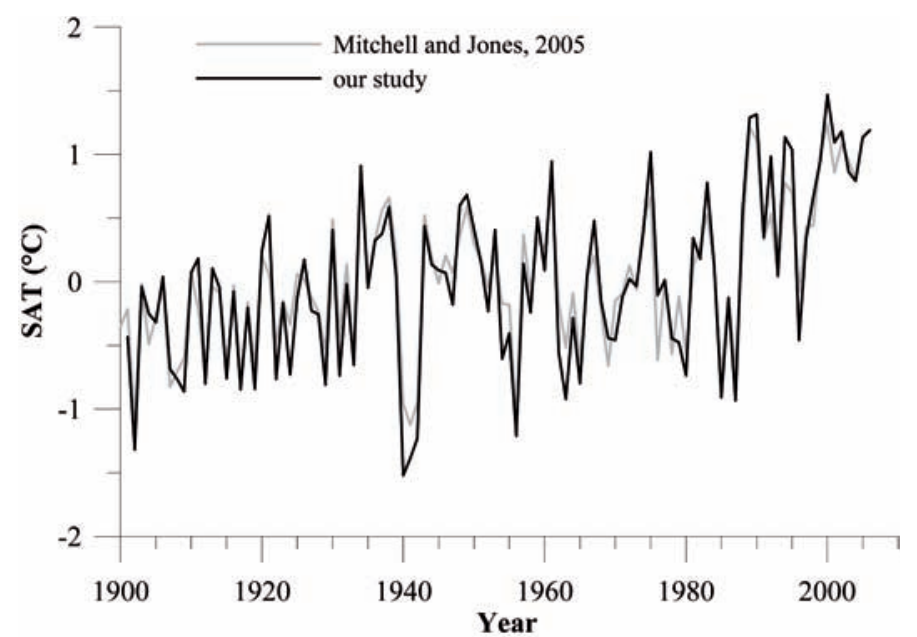

Figure 4. Mean temperatures for Europe. Black, by averaging all of the analyzed data series; gray, from Mitchell and Jones [2005].

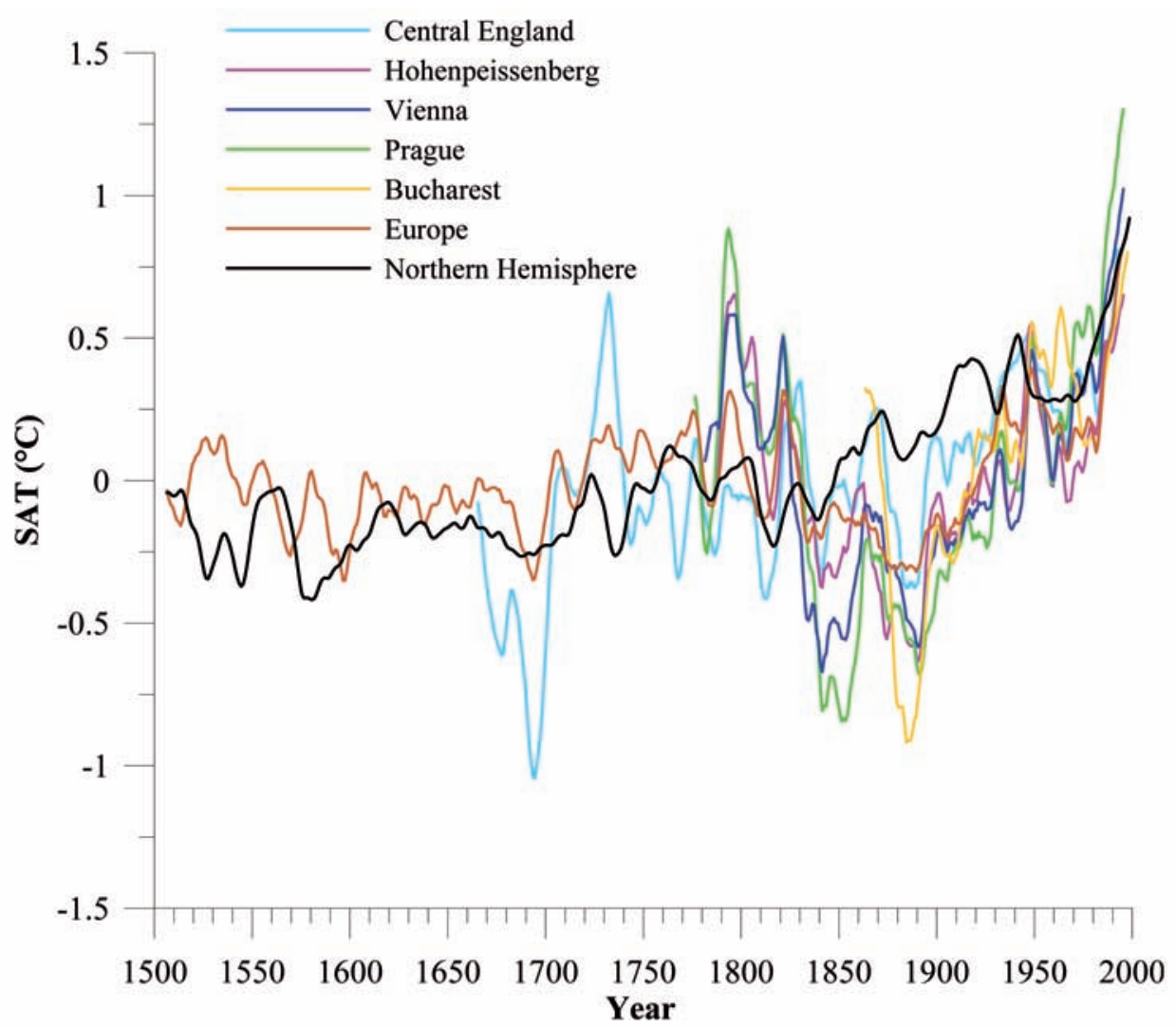

Figure 5. Interdecadal trends of anomalies in the surface-air temperatures, relative to the means over the time interval of 1961-1990, for several individual stations, for Europe, and for the northern hemisphere.

smoothed using a running window of 11 years (Figure 3, red line), which defines the interdecadal trend, T11. Going further and filtering with a running window of 22 years applied to T11, we obtain the smoothed time series, T22, called the centennial trend in the data, given in Figure 3 (blue line). The differences of T-T11 and T11-T22 would depict the 11-year sunspot and the Hale-cycle-related variations, respectively.

Having in mind that the instrumental period is very short for studying climate change and its effects, various proxy data have been used for temperature reconstruction in the past. Reconstructed temperature data have given information about climate conditions at particular locations through records of physical, biological or chemical responses to these conditions. Some reconstructions have given information dating back hundreds of years, which make them suitable for analyzing long-term climate variations and their correlation with solar activity.

For completeness, we included in our analysis several published reconstructions for certain areas; namely Europe (Mitchell and Jones [2005], based on instrumental data for 

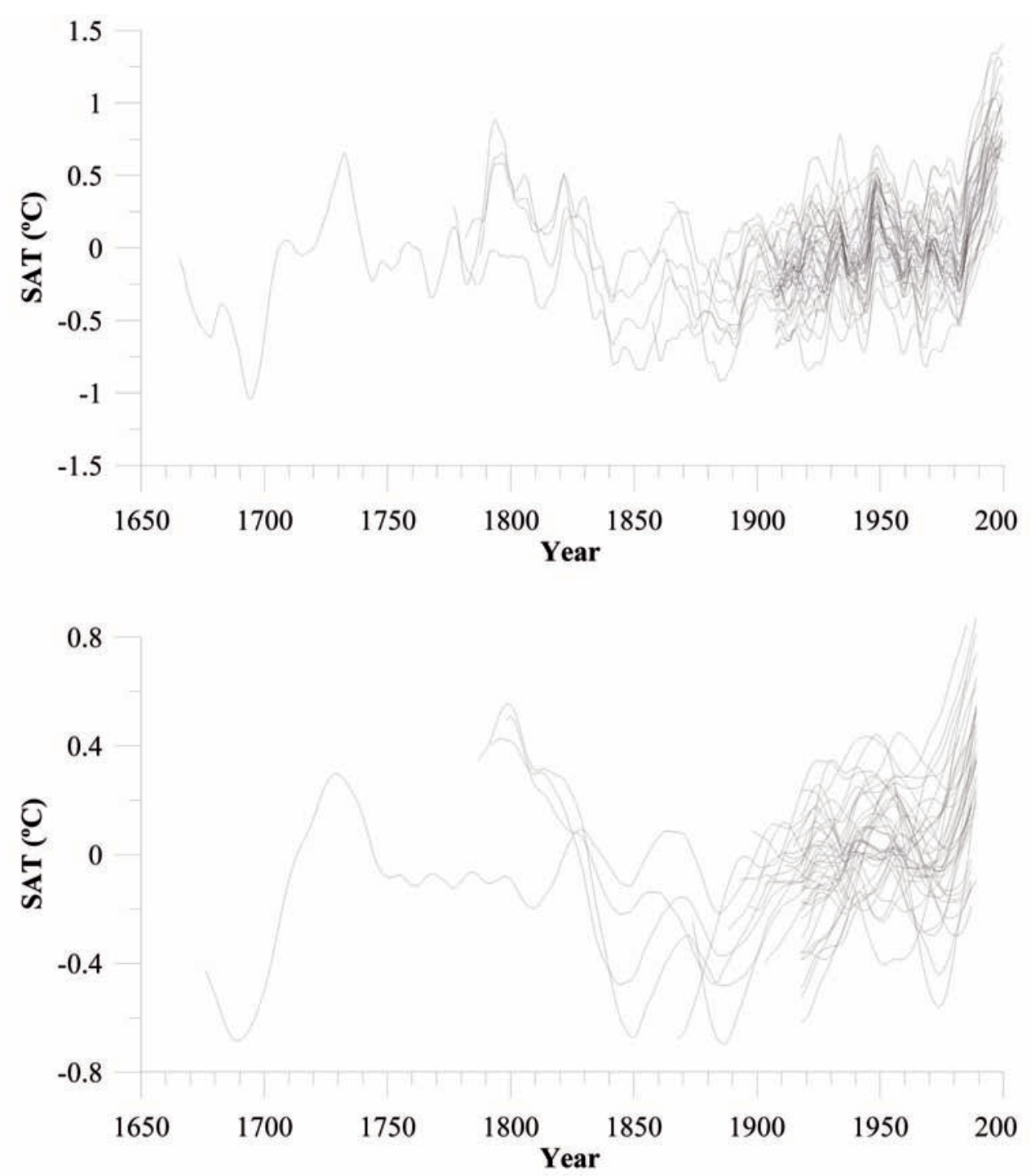

Figure 6. Surface-air temperatures at all of the stations studied in Europe. Upper panel, interdecadal trends; lower panel, centennial trends.

1900-2004, and reconstructions by Luterbacher et al. [2004] and Xoplaki et al. [2005] for 1500-1900) and the northern hemisphere (Moberg et al. [2005] for 1500-1979, based on tree ring and lake/ocean sediment data; Jones et al. [2006] for 1980-2005, as instrumental data).

\section{Results}

As can be seen in Figures 2 and 3, there is a general increase in surface-air temperature superimposed on shortterm and long-term variations. The strong minimum in temperature in 1940, which is visible at all of the analyzed stations (Figure 2), and then the increasing trend in the last two decades of the 20th century can be noted. In spite of the regional climatic differences at the European scale, the variations are similar at all of the analyzed stations, so that an average temperature for the 35 meteorological stations has been calculated and then compared with the average temperature for Europe given by Mitchel and Jones [2005] based on instrumental data (grided monthly data in a $0.5^{\circ}$ network). This comparison is shown in Figure 4. There are no phase differences between the two temperature series, but there are small amplitude differences, not larger than $0.5^{\circ} \mathrm{C}$. The spatial coherency of the European data has been estimated to be of the order of 3,000 km by Le Mouël et al. [2008], in a study on 44 stations.

The evolution of the individual weather-station records in comparison to the mean temperatures calculated for certain areas of the globe, such as the European continent and the northern hemisphere, is presented in Figure 5 in terms of the interdecadal trends. The data have been plotted from the four stations (central England, Hohenpeissenberg, Vienna and Prague) that date back to the end of the 16th and the middle of the 18th centuries, and from one individual station over the Romanian territory, at Bucharest, that dates back to 1857; reconstructions of temperatures for Europe and for the northern hemisphere are also shown. The similarities in the variations at individual stations and the notable amplitude differences with respect to the mean values for the whole of Europe or for the northern hemisphere can be seen. We also note that between 1930 and 1940 the northern hemisphere average showed a peak, while the temperature at individual stations and the European 

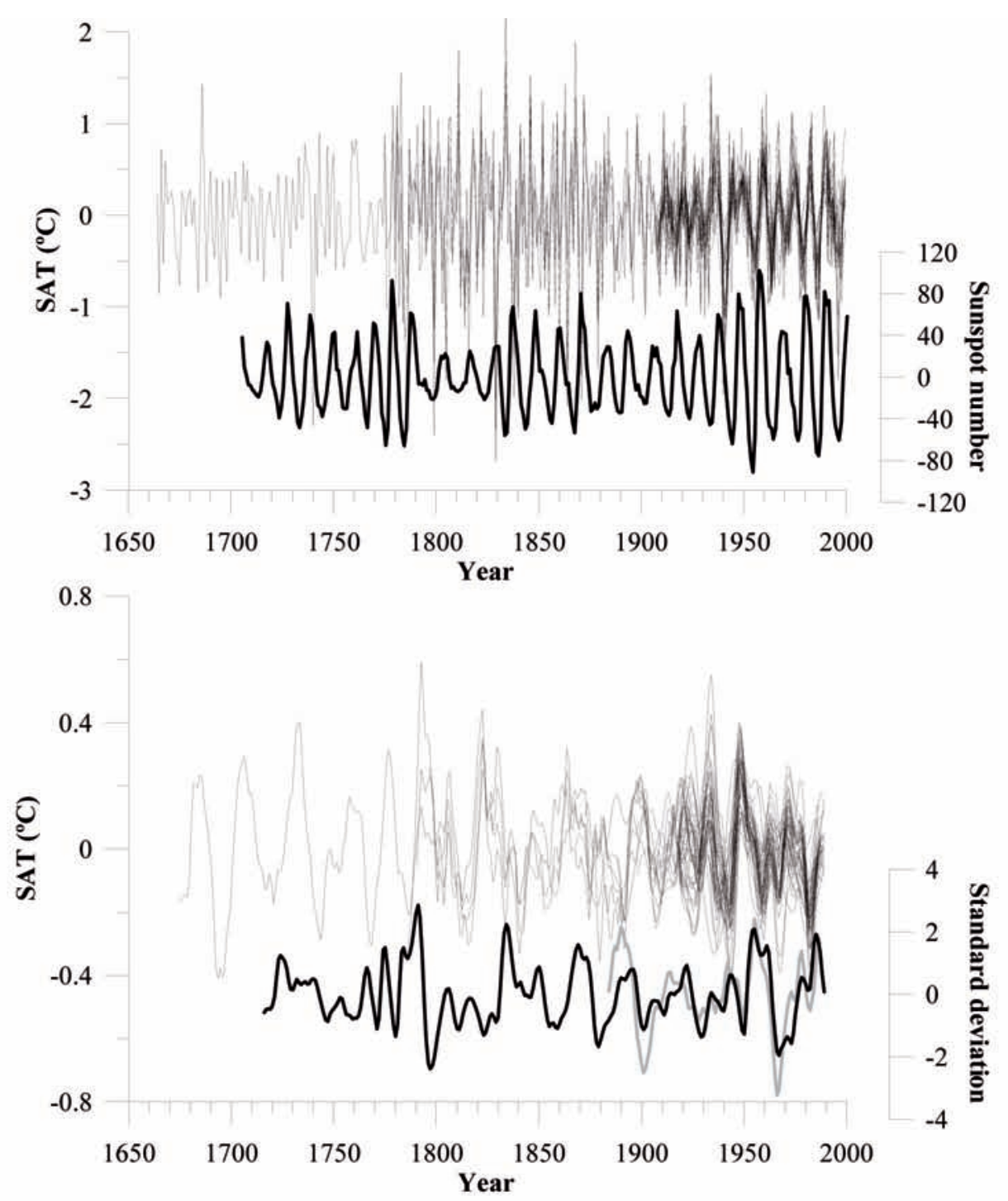

Figure 7. Surface-air temperatures at the European stations. Upper panel, 11-year solar cycle; thick black line, comparison with the 11-year solar-activity cycle. Lower panel, 22-year related variations; thick black and gray lines, comparisons with the 22-year variations in the solar and geomagnetic activities, respectively.

average decreased.

Figure 6 shows the 11-year (upper panel) and 22-year (lower panel) running averages of the temperatures from the 39 individual stations. The main feature of these graphs is the similarities in the interdecadal and centennial trends, with no, or only slight, phase differences, although with significant amplitude differences between stations. Details in the centennial trend (Figure 6, lower panel) will be discussed in the next section.

The corresponding variations, namely the 11-year solar cycle and the 22-year related variations, are presented in Figure 7. Again, the coherency of the variations between the stations is remarkable. The 11-year sunspot-cycle-related variations (Figure 7, upper panel) show amplitudes from maximum to minimum of about $3{ }^{\circ} \mathrm{C}$ since about 1940 . Smaller amplitudes $\left(2^{\circ} \mathrm{C}\right)$ characterize the time period from 1870 until 1940, when a sharp minimum occurred and the amplitude of these variations changed. In the interval 17801870 , the amplitude of the 11-year temperature variations was the highest of all of these times, at about $4{ }^{\circ} \mathrm{C}$ to $5{ }^{\circ} \mathrm{C}$. In the earlier times, the temperature record for central England shows temperature variations with smaller amplitudes, of about $1{ }^{\circ} \mathrm{C}$. Generally, the central England time series shows lower amplitudes in comparison with the other four long time series. However, a closer look at the central England time series alone reveals the same differences in the character of the variability, clustered as indicated above. We note that episodes of smaller amplitudes can be found among the highamplitude variations seen between 1780-1870, although the general impression relating to this time interval stems from the series of minima reaching $-1.5^{\circ} \mathrm{C}$ to $-2.5^{\circ} \mathrm{C}$, which is accompanied by several maxima greater than $+1{ }^{\circ} \mathrm{C}$, one of which reached a value as high as $+2{ }^{\circ} \mathrm{C}$.

One obvious possible cause for these large differences in character during the periods mentioned might have an instrumental origin. The errors in the data propagate in the curves of Figure 7, although they are more likely to showup in the 11-year signals than in the 22-year ones, as the latter is a result of double smoothing of the initial data. However, the coherence of the 11-year signals in all of the time series 
speaks in favor of a certain uniformity in equipment and measurement accuracy. We were not able to check the dates of major changes in equipment, and whether they extended over the entire study area at the same time, such that they might explain these differences in the character of the variability. For the moment, we favor variability changes at the interdecadal timescale as the origin of the character differences shown in Figure 7 (upper panel). Long-term variability changes at the 22-year scale in the high-frequency temperature disturbances seen in the daily maxima, minima and average temperature values have already been described by Le Mouël et al. [2008, 2009] for several climate regions, including Europe and the USA, based on a large network of stations (44 and 153, respectively), and in Australia (preliminary, 5 stations). Non-linear techniques were used, such as squared inter-annual differences and lifetime estimators. A similar statistical study on 11-year variations will be undertaken elsewhere, but the possible results will be hampered by the worse statistics of these data.

The amplitude of the 22-year temperature variations (peak to trough), shown in Figure 7 (lower panel) does not change as much in the time period analyzed, varying in the range of $0.6^{\circ} \mathrm{C}$ to $0.8^{\circ} \mathrm{C}$. However, enhancements of the 22 year variations can be noted around 1800 and 1940. The strong decrease in the temperatures around 1940 and the increase in the 1980's seen in Figures 2 and 4 appear as a result of the superposition of minima of both the sunspotcycle-related variations and of the 22-year-related variations.

\section{Discussion}

As we deal with 2-3-centuries-long data time series, and the way we have plotted them in Figure 2, this allows century-long variations to be noted, as well as the coherent variations at the 11-year and 22-year time scales illustrated in Figure 7. In their analysis of the secular evolution of temperature disturbances for 44 temperature time series starting after 1900, Le Mouël et al. (2008) noted that on the one hand, all of the individual station curves showed significant energy in the 3-15-year-period range, and that much of the spectral content of the temperature curves is highly correlated at the continental scale $(\sim 3,000 \mathrm{~km}$, as indicated in the previous section). On the other hand, starting at $\sim 1908$, they saw only two features in the overall mean curve (their Figure 6, which is similar to the mean curves plotted in the present Figure 4): namely, the intense temperature drop with a minimum in 1940-1941 also mentioned in the previous section, and a sharp temperature rise by almost $1{ }^{\circ} \mathrm{C}$ in $\sim 1987$. With our enlarged timeperspective on the data, we can no longer interpret the 1910-1985 time interval as a flat evolution of European temperature against which these two features stick out. Instead, both of these are the result of the addition of the 11 -year and the 22-year signals in the data, on a background
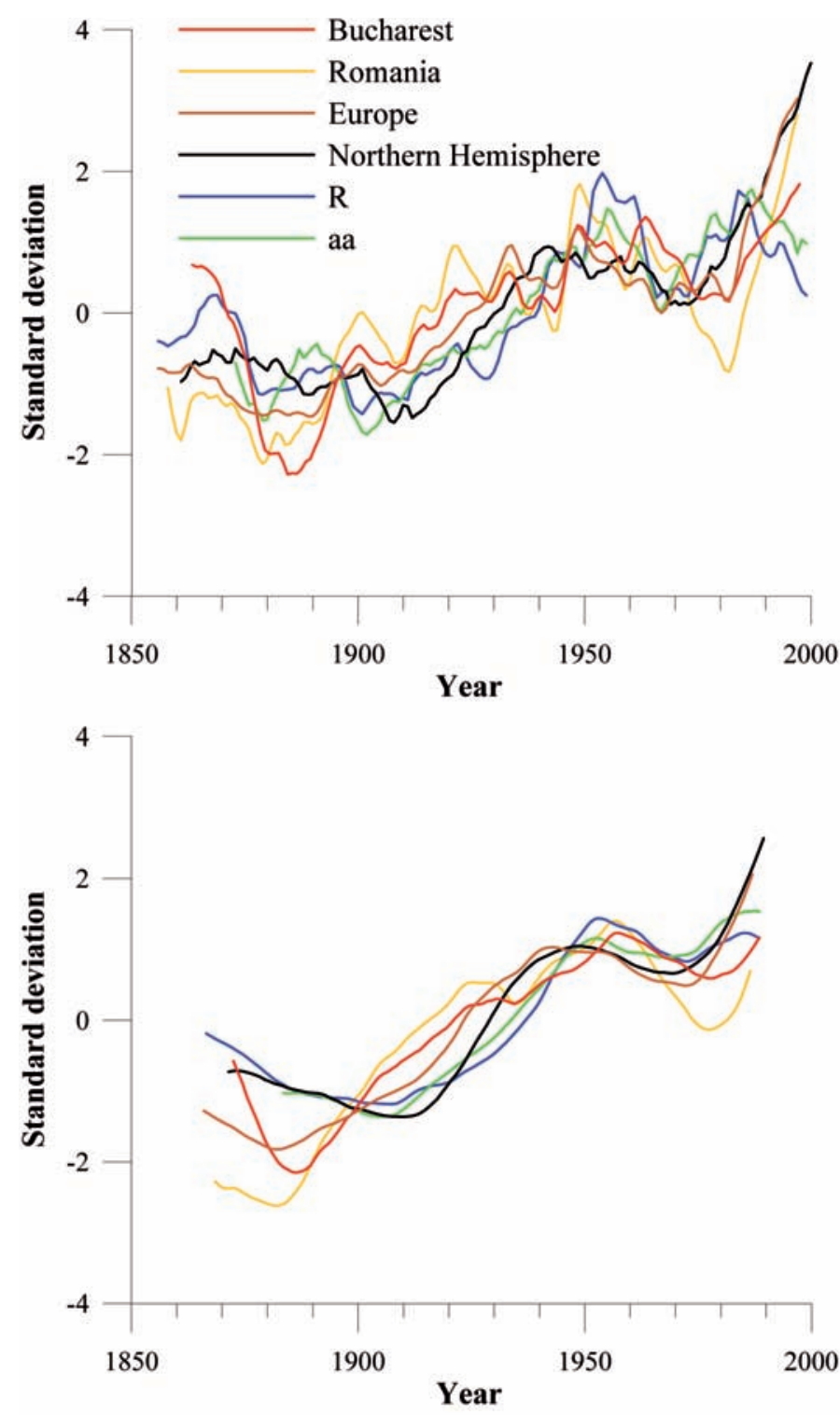

Figure 8. Temperatures at Bucharest and the averages for Romania, Europe and the northern hemisphere, compared to the solar, R, and geomagnetic, aa, index. Upper panel, interdecadal trends; lower panel, centennial trends. Curves are reduced to their means over the common time intervals and scaled with their standard deviations about the mean as a unit.

of slowly varying temperatures at large timescales, which increased between $\sim 1880$ and 1950, and decreased between 1950 and 1970-1980, and have increased since. Several years of additional data would be necessary to decide on the temperature evolution after 2000. We will refrain here from interpreting the long-term evolution of temperature by means of straight-line segments, as we prefer to discuss the data as a result of superimposition of signals evolving at various time scales, some of which are linked to solar activity.

That the variations shown in Figure 7 are indeed linked to the solar/geomagnetic activity is shown by a comparison with the corresponding variations seen in the sunspot $(\mathrm{R})$ and the geomagnetic aa index time series, processed in the same way as the temperature. In Figure 7, the 11-year component of $\mathrm{R}$ and the 22-year component of both $\mathrm{R}$ and aa are plotted along with the 11-year and 22-year variations in temperatures (Figure 7, 


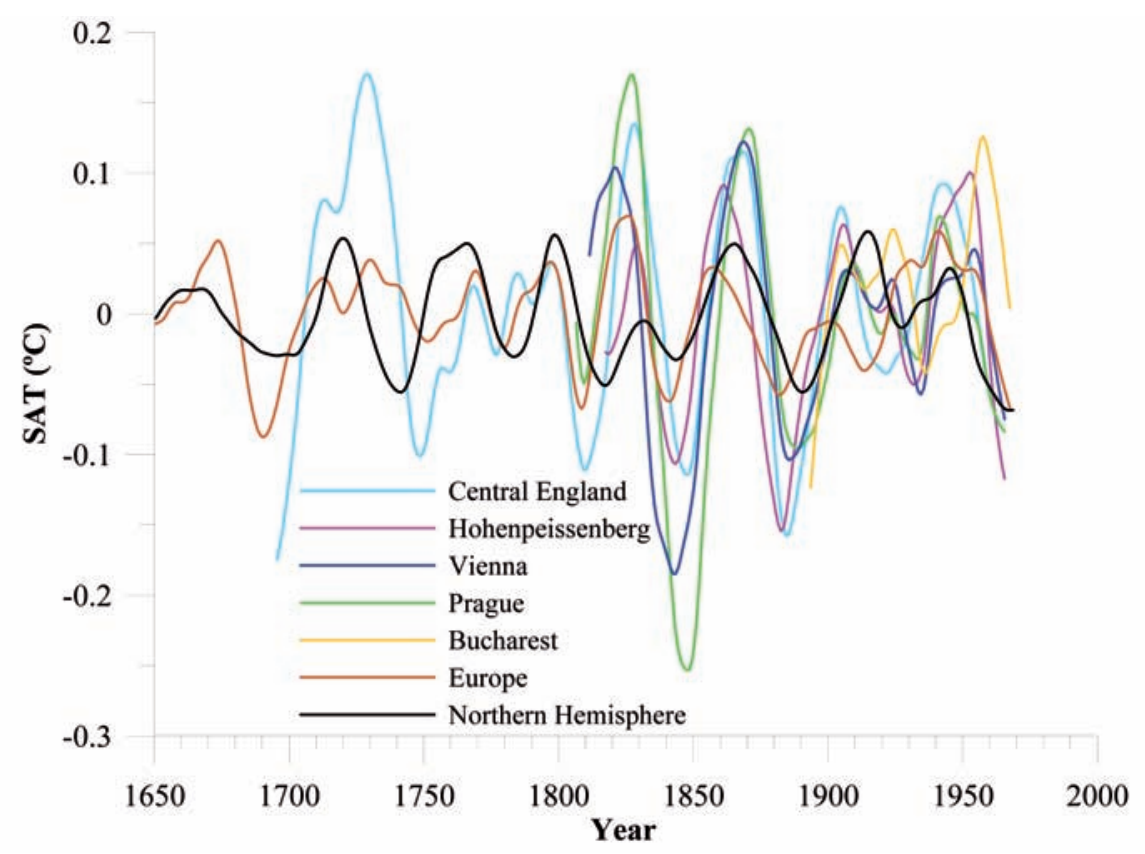

Figure 9. The $\sim 40$-year variation in surface-air temperatures for several individual stations, for Europe and the northern hemisphere.

upper and lower panels, respectively). The comparison in the case of the 11-year variations reveals that the well-defined 11year signal in the temperatures correlated over the entire study area is changing the type of correlation with the 11-year signal in solar activity, from positive to negative, rather soon after the Dalton minimum. The longest correlated part relates to cycles 16-22, with an interruption during the special cycle 20 , for which two temperature peaks are observed, and the longest anti-correlated part relates to cycles 7-11. The temperature peak corresponds rather often to the descending phase of a solar cycle, which indicates possible connections to the second peak in a cycle characteristic of geomagnetic activity. A detailed study of these aspects is under development [Dobrica and Demetrescu, in preparation]. A phase difference of a few years might be present in the case of the 22-year variations, as also suggested by the analysis of only the Romanian data of Dobrica et al. [2009]. We note here that for the time interval 1880-2000, Souza Echer et al. [2009] showed similar behavior of the temperature using a multiresolution analysis of global surface-air temperatures and solar activity: solar activity correlation with the 11-year signal, and a strong correlation with the 22-year variation, although with a zero lag in the latter case.

To directly compare the interdecadal and centennial trends in temperature data and in solar/geomagnetic activity data, Figure 8 shows the respective trends in the cases of R, aa, and three different types of temperature data; namely an individual station, the average temperature for a localized area (Romania), the average at the European continental scale, and the average for the northern hemisphere. The curves are reduced to their means over the common time interval and scaled with their standard deviations about the mean as a unit. Certain differences can be noted regarding the influence of the averaging area size, especially concerning the faster increases in temperatures in comparison with the solar/geomagnetic activities before 1950. The discrepancy in the trend after 1980 is visible in these plots, too, which envisages the possible emergence of the effects of the anthropogenic green-house gases, as seen by Le Mouël et al. [2005] and confirmed by Dobrica et al. [2009].

The faster increase in temperature in comparison to solar/geomagnetic activities before 1950 that is seen in Figure 8 (equivalent to the temperature leading the solar/geomagnetic activities) deserves particular attention. It was first noted by Friis-Christensen and Lassen [1991], and explained in terms of possible inaccuracies in the temperature data, an explanation maintained by Le Mouël et al. [2005]. We shall elaborate here on the observation by Dobrica et al. [2009], that a $\sim 40$-year oscillation was present in the London data. This can be seen for all of the stations with records going back before 1900 in Figure 6 (lower panel), although we will clarify this in the following.

Filtering further the time series shown in Figure 6 (lower panel; i.e. T22) with a 40-year running window average, to obtain T40, the difference T22-T40 plotted in Figure 9 shows a $\sim 40$-year variation with a significant amplitude of $0.2^{\circ} \mathrm{C}$ to $0.3{ }^{\circ} \mathrm{C}$ peak to trough. An experiment with running windows of 30,60 and 88 years, as several periodicities that are occasionally mentioned in the literature, yielded the same output, namely, the $\sim 40$-year variation, with almost the same amplitudes. As a similar variation was not found in the solar/geomagnetic data [Demetrescu and Dobrica 2008], we conclude that this is related to the atmospheric dynamics alone. A further conclusion is that the strong solar/geomagnetic signal seen at several timescales, namely the inter-annual [Le Mouël et al. 2008, 2009] and the 11-year 
and 22-year [Dobrica et al. 2009; the present paper] timescales, might not be present at longer timescales. As such, the longterm evolution of temperature as depicted by filtered time series like those in Figure 8 can no longer be interpreted as proof of solar/geomagnetic activity effects at the centennial timescale. They contain long-term variations driven by internal atmospheric processes that might mask a solar/ geomagnetic signature, if any, at timescales longer than that of 22 years. However, de Jager and Duhau [2009], in a comparison of tropospheric temperatures as represented by seven northern hemisphere temperature datasets, Moberg et al. [2005] included, with the equatorial and polar solar magnetic fields, found out that the residuals of their model have significant amplitudes in the last four centuries as large as $0.2{ }^{\circ} \mathrm{C}$ to $0.3^{\circ} \mathrm{C}$ and point to the possibility that they might be related to the solar activity at the Gleissberg-cycle timescale.

\section{Conclusions}

In all, 39 temperature records from European meteorological stations with long activities were analyzed in terms of their relationships with variations in solar and geomagnetic activities, as represented by the sunspot number, R, and by the geomagnetic aa index. Annual mean data were used. Strong coherent solar signals are found at Schwabe and Hale solar-cycle timescales. The interdecadal and centennial trends in the data differ significantly from the corresponding trends in the solar/geomagnetic data, which indicates the presence of temperature variations at the 3040-year timescale that might be related to the internal dynamics of the atmospheric system.

The 11-year sunspot-cycle-related variations showed amplitudes from maximum to minimum of about $3{ }^{\circ} \mathrm{C}$ in the instrumental era. Smaller amplitudes $\left(2^{\circ} \mathrm{C}\right)$ characterized the time period from 1870 to 1940 , when a sharp minimum occurred, and the amplitude of these variations changed. In the interval of 1780-1870, the amplitude of the 11-year temperature variations were the highest of all of these times, at about $4{ }^{\circ} \mathrm{C}$ to $5{ }^{\circ} \mathrm{C}$, while in the earlier times, amplitudes of only about $1{ }^{\circ} \mathrm{C}$ were seen. The amplitude of the 22 -year temperature variations ranged between $0.6{ }^{\circ} \mathrm{C}$ and $0.8{ }^{\circ} \mathrm{C}$, peak to trough. However, enhancements in the 22-year variations can be noted around 1800 and 1940 . The $\sim 40$-year variation related to the internal atmospheric processes shows amplitudes that reached $0.3^{\circ} \mathrm{C}$, peak to trough. Occasionally these three variations concur in producing strong, sharp changes, such as the 1940 temperature decrease and the 1987 temperature increase recorded by the European stations.

Differences in interdecadal and centennial temperature trends were noted regarding the influence of the averaging area size, especially concerning the faster increase in temperatures in comparison to the solar/geomagnetic activities before 1950 .

The results of the present study indicate the importance of the time perspective used with climate data when analyzing their long-term behavior.

Acknowledgements. This study was supported by the Ministry of Education and Research, Romania (PN-II CNCSIS-UEFISCSU IDEI $151 / 2007)$. We thank Cristina Pirvutoiu for help with the temperature databank, and Cornelis de Jager and an anonymous reviewer for valuable suggestions to improve the original manuscript.

\section{References}

Bucha, V. and V. Bucha Jr (1998). Geomagnetic forcing of changes in climate and in the atmospheric circulation, $\mathrm{J}$. Atmos. Sol.-Terr. Phy., 60 (2), 145-169.

Bucha, V. and V. Bucha Jr (2002). Geomagnetic forcing and climatic variations in Europe, North America and in the Pacific Ocean, Quartern. Int., 91 (1), 5-15.

Cliver, E.W., V. Boriakoff and J. Feynman (1998). Solar variability and climate change: Geomagnetic aa index and global surface temperature, Geophys. Res. Lett., 25 (7), 1035-1038.

Courtillot, V., Y. Gallet, J.-L. Le Mouël, F. Fluteau and A. Genevey (2007). Are there connections between the Earth's magnetic field and climate?, Earth Planet. Sc. Lett., 253, 328-339; doi: 10.1016/j.epsl.2006.10.032.

de Jager, C., and I. Usoskin (2006). On possible drivers of Suninduced climate changes, J. Atmos. Sol.-Terr. Phy., 68, 2053-2060; doi: 10.1016/j.jastp.2006.11.013.

de Jager, C., and S. Duhau (2009). Episodes of relative global warming, J. Atmos. Sol.-Terr. Phy., 71 (2), 194-198; doi: $10.1016 /$ j.jastp.2008.05.019.

Demetrescu, C., and V. Dobrica (2008). Signature of Hale and Gleissberg solar cycles in the geomagnetic activity, J. Geophys. Res., 113, A02103; doi:10.1029/2007JA012570.

Dobrica, V., C. Demetrescu, C. Boroneant and G. Maris (2009). Solar and geomagnetic activity effects on climate at regional and global scales: Case study-Romania, J. Atmos. Sol.-Terr. Phy., 71 (17-18), 1727-1735; doi: 10.1016/j.jastp.2008.03.022.

El-Borie, M.A., and S.S. Al-Thoyaib (2006). Can we use the aa geomagnetic activity index to predict partially the variability in global mean temperatures?, Int. J. Phy. Sci., 1 (2), 067-074.

Friis-Christensen, E., and K. Lassen (1991). Length of the solar cycle: An indicator of solar activity closely associated with climate, Science, 254, 698-700.

Gallet, Y., A. Genevey and V. Courtillot (2003). On the possible occurrence of 'archaeomagnetic jerks' in the geomagnetic field over the past three millennia, Earth Planet. Sc. Lett., 214 (1-2), 237-242.

Haigh, J.D. (2007). The Sun and the Earth's Climate, Living Reviews in Solar Physics, 4, 1-64.

Johnson, R.W. (2009). Enhanced wavelet analysis of solar magnetic activity with comparison to global temperature and the Central England Temperature record, J. Geophys. Res., 114, A05105; doi: 10.1029/2009JA014172. 
Jones, P.D., D.E. Parker, T.J. Osborn and K.R. Briffa (2006). Global and hemispheric temperature anomalies-land and marine instrumental records. In: Trends: A Compendium of Data on Global Change. Carbon Dioxide Information Analysis Center, Oak Ridge National Laboratory, U.S. Department of Energy, Oak Ridge, Tenn., U.S.A.

Korte, M., and C. Constable (2005). The geomagnetic dipole moment over the last 7000 years - New results from a global model, Earth Planet. Sc. Lett., 236, 348-358.

Labitzke, K., and H. van Loon (1988). Associations between the 11-year solar cycle, the QBO and the atmosphere. I. The troposphere and stratosphere in the northern hemisphere in winter, J. Atmos. Terr. Phys., 50, 197-206.

Labitzke, K. (2005). On the solar cycle-QBO relationship: A summary, J. Atmos. Terr. Phys., 67, 45-54.

Le Mouël, J.-L., V. Kossobokov and V. Courtillot (2005). On long-term variations of simple geomagnetic indices and slow changes in magnetospheric currents: The emergence of anthropogenic global warming after 1990?, Earth Planet. Sc. Lett., 232, 273-286.

Le Mouël, J.-L., V. Courtillot, E. Blanter and M. Shnirman (2008). Evidence for a solar signature in 20th century temperature data from the USA and Europe, C. R. Geosci., 340, 421-430; doi: 10.1016/j.crte.2008.06.001.

Le Mouël, J.-L., E. Blanter, M. Shnirman and V. Courtillot (2009). Evidence for solar forcing in variability of temperatures and pressures in Europe, J. Atmos. Sol.-Terr. Phy., 71, 1309-1321; doi: 10.1016/j.jastp.2009.05.006.

Luterbacher, J., D. Dietrich, E. Xoplaki, M. Grosjean and H. Wanner (2004). European seasonal and annual temperature variability, trends and extremes since 1500 , Science, 303, 1499-1503.

Manley, G. (1974). Central England temperatures: monthly means 1659 to 1973, Q. J. Roy. Meteor. Soc., 100, 389-405.

Mayaud, P.N. (1972). The aa indices: a 100-year series characterizing the geomagnetic activity, J. Geophys. Res., 77, 6870-6874.

Mayaud, P.N. (1980). Derivation, meaning, and use of geomagnetic indices, In: Geophysical Monograph, 22, AGU, Washington, D.C., 154 pp.

Mitchell, T., and P.D. Jones (2005). An improved method of constructing a database of monthly climate observations and associated high-resolution grids, Int. J. Climatol., 25, 693-712.

Moberg, A., D.M. Sonechkin, K. Holmgren, N.M. Datsenko and W. Karlén (2005). Highly variable Northern Hemisphere temperatures reconstructed from low- and highresolution proxy data, Nature, 433, 613-617.

Parker, D.E., T.P. Legg and C.K. Folland (1992). A new daily central England temperature series, 1772-1991, Int. J. Climatol., 12, 317-342.

Scafetta, N., and B.J. West (2007). Phenomenological reconstructions of the solar signature in the Northern Hemi- sphere surface temperature records since 1600 , J. Geophys. Res., 112, D24S03.

Solanki, S.K., I.G. Usoskin, B. Kromer, M. Schüssler and J. Beer (2004). Unusual activity of the Sun during recent decades compared to the previous 11,000 years, Nature, 431, 1084-1087.

Souza Echer, M.P., E. Echer, D.J.R. Nordemann, N.R. Rogozo (2009). Multi-resolution analysis of global surface air temperature and solar activity relationship. J. Atmos. Sol.Terr. Phy., 71, 41-44; doi: 10.1016/j.jastp.2008.09.032.

Svalgaard, L., and E.W. Cliver (2005). The IDV index: its derivation and use in inferring long-term variations of the interplanetary maagnetic field strength, J. Geophys. Res., 110, A12103; doi: 10.1029/2005JA011203.

Svalgaard, L., and E.W. Cliver (2007). The InterHourly Variability (IHV) index of geomagnetic activity and its use in deriving the long-term variation of solar wind speed, J. Geophys. Res., 112, A10111; doi: 10.1029/2007JA012437.

Usoskin, I.G., S.K. Solanki, M. Schüssler, K. Mursula and K. Alanko (2003). Millenium-scale sunspot number reconstruction: Evidence for an unusually active Sun since the 1940s, Phys. Rev. Lett., 91; doi: 10.1103/PhysRevLett. 91.211101.

Usoskin, I.G., M. Schussler, S.K. Solanki and K. Mursula (2005). Solar activity, cosmic rays, and Earth's temperature: A millennium-scale comparison, J. Geophys. Res., 110, A10102; doi: 10.1029/2004JA010946.

Usoskin, I.G., S.K. Solanki and M. Korte (2006). Solar activity reconstructed over the last 7000 years. The influence of geomagnetic field changes, Geophys. Res. Lett., 33, L08103; doi: 10.1029/2006GL025921.

Valev, D. (2006). Statistical relationships between the surface air temperature anomalies and the solar and geomagnetic activity indices, Phys. Chem. Earth, 31, 109-112.

van Loon, H., G.A. Meehl and D.J. Shea (2007). Coupled airsea response to solar forcing in the Pacific region during northern winter, J. Geophys. Res., 112, D02108.

Xoplaki, E., J. Luterbacher, H. Paeth, D. Dietrich, N. Steiner, M. Grosjean and H. Wanner (2005). European spring and autumn temperature variability and change of extremes over the last half millennium, Geophys. Res. Lett., 32, L15713.

\footnotetext{
${ }^{\star}$ Corresponding author: Venera Dobrica, Institute of Geodynamics, Romanian Academy, Bucharest, Romania; e-mail: venera@geodin.ro.
}

C 2010 by the Istituto Nazionale di Geofisica e Vulcanologia. All rights reserved. 